\title{
The Performance of Ball during Flight Incorporate lift Force, Drag, Gravity and high Turning Velocity Trajectories Tracking Prediction
}

\author{
Umakant Bhaskrrao Gohatre, C. Ram Singla, Venkat P Patil
}

\begin{abstract}
The abilities on the journey in a bag contain force, travel and gravitational. A ball with a high speed of turn has an alternate elevator and drag according to the turn rate and number of Reynolds. Furthermore, the drag power of balls is mainly distinctive as their magnitude, depth and amount imply. All the less, the golf reproductions do not reflect these differences. "This paper offers the approach to altering a track-story distance of the Golf Ball, which will be imitated by its drag depending on changes to the Reynolds Number. Similarly, because in the real world the separation from the ball from the flight can change depending on temperature, adhesiveness and height, these changes are to be observed in appropriate games. The 3 dimensional (3-D) flight of a golfing ball at taking into consideration the Magnus effect is studied inside the paper. For this purpose it is composed a gadget of six nonlinear differential equations. To decide the 3-d orientation of the ball the rotations round all three axes are given by way of the so-called Cardin angles instead of classical Euler ones. The high nonlinear system differential equations are solved numerically with the aid of a special application created in the MATLAB - Simulink surroundings. It is founded the legal guidelines of motion, velocities and accelerations on all six coordinates, as well as the projections of trajectory at the 3 coordinate planes.
\end{abstract}

Keywords: Three dimensional flights, golf ball, drag and lift forces, Magnus effect, spinning ball, flying trajectory.

\section{INTRODUCTION}

In a present time a ton of productions about investigations of a golf ball trip in air condition are known. An enormous piece of the papers can be summed up as research on the optimal design (in general) of the ball flight however different investigations can be relegated to some particular fields. "The first of them is identified with the biomechanics of the stroke with a club from the side of the golfer" $[1,2,3$, etc.].

Revised Version Manuscript Received on 10, September 2019.

UmakantBhaskarraoGohatre, Electronics and Communication Engineering Department, Madhav University, Pindwara, Rajasthan, India.(Email: umakantbhaskar@gmail.com)

Dr. C. Ram Singla, Electronics and Communication Engineering Department, Madhav University, Pindwara, Rajasthan, India.(Email: Crslibra1010@gmail.com)

Venkat P. Patil, Electronics and Communication Engineering Department, Madhav University, Pindwara, Rajasthan, India.(Email: bkvpp@rediffmail.com)
In the time of genomics and proteomics, peptide based immunization structuring and immunodiagnosis is the best

for infections running from jungle fever to disease. It does basically require distinguishing proof of areas in theThe

distributions from the subsequent field manage the effect between the club head and the ball and the impact of this communication on the ball trip after that $[4,5$, etc.]. The other gathering of creators put the complement on the examination of the mechanical properties and damping attributes of the balls materials $[6,7,8$, etc.]. Besides in a portion of the investigations $[9,10,11$, etc. $]$ the emphasis is on the area, thickness, size and state of the ball dimples, just as their effect on the drag and lift coefficients in reliance of the ball speed and Reynolds number. By the other hand, a component of most investigations is that the trip of the golf ball noticeable all around condition is considered as a material point movement $[12,13,14,15$, etc. $]$.

One of the purposes of this flying path, a medium term for golf, relates to how the shots impacts. Besides the immediate lines there are other kinds of trajectories: pick, click, click and trimmed as shown in Fig. 1. A sweat is when a golfer begins to move a finger without shifting laterally to his planned goal and the bat begins shifting laterally at his remaining target,[2-4] as well. A cap twist is a crochet where the table bends directly to the right because of a few corner twists. A part is a matrix trajectory that passes the key from left to right due to the lateral rotation of the key on the other hand of the cabinet to obtain the result of the button[5-11]. The way that the golf ball is a generally little in size. In the previously mentioned papers the golf ball flight is portrayed by three differential conditions about the three tomahawks of the Cartesian organize framework. Moreover a portion of the arrangements $[9,10]$ allude to golf ball movement just in one plane (the vertical one One answer for such 3D model is displayed in [16] at considering the tennis ball flight. Here it is imperative to make reference to that with comparative scientific models which are linearized as for the precise pivots are considered the $3 \mathrm{D}$ vibrations of the individual mobile pieces of the machine structures, or even whole totals associated by versatile components 


\section{THE PERFORMANCE OF BALL DURING FLIGHT INCORPORATE LIFT FORCE, DRAG, GRAVITY AND HIGH TURNING VELOCITY TRAJECTORIES TRACKING PREDICTION}

\section{STUDY ABOUT CHARACTERISTICS OF BALL}

To begin an investigation of the golf ball flight it is important to know the geometrical what's more, mechanical qualities of the ball. "The hustling golf ball has a mass close to $3459310, \square[\mathrm{kg}]$ and has a width not less than $4,267.102$ $\square$ [m]. The golf ball should likewise have the fundamental properties of a circularly even body [18].

It implies that the ball itself must be circular and must have a even course of action of dimples on its surface".

"Three layered balls regularly have Surlyn or a gentler polyurethane spread and a mantle layer of elastic windings around a elastic center. Four layered balls moreover have an inward spread made of a mix of incomers and an external spread made of Elastomer or Balata. Having more layers makes a difference to effectively actualize the ball turn and Magnus impact. In the present paper will be considered the old style instance of two layered golf body, concerning the examination the accompanying suspicions are presented: the golf ball is a strong circle with a normal span $2 \mathrm{R} 2,14.10$ [m],

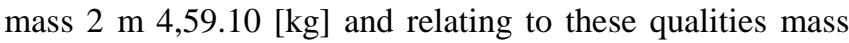
snapshot of latency J [kg.m2].
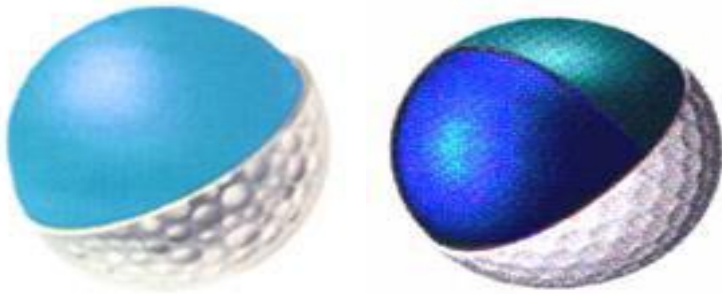

Fig. 1: Constructions of golf ball

The golf balls can be diversely planned (Fig.1). The most utilized ones are two layers balls: an enormous internal center of a thick material (elastic or comparative) and a slender hard spread (cutproofSurlyn) as a second external layer. These balls combine stability with extremely low turning and the most extreme separation. Late development of golf balls is multi-faceted (four layers, three). From the photos, different pitches of the golf balls have been distinguished by their streamline circuit.

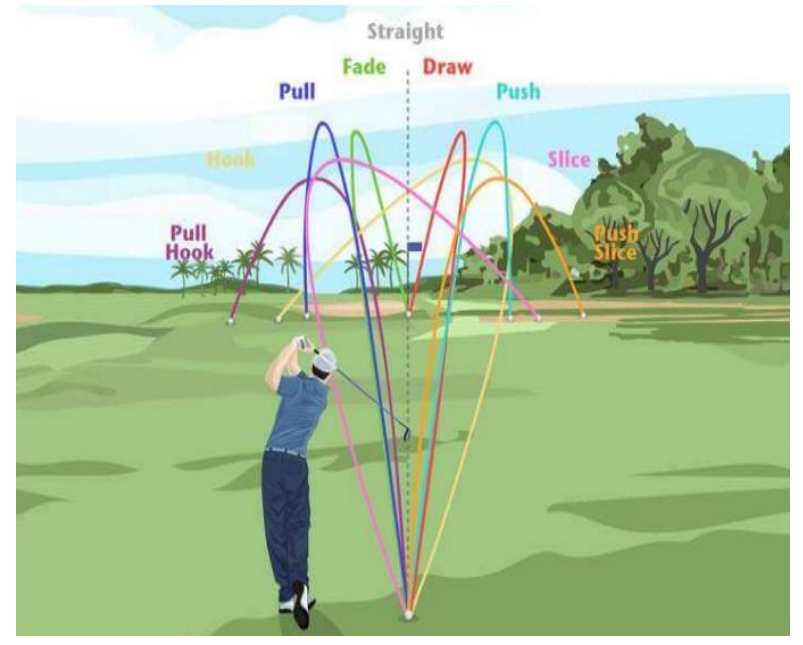

Fig. 2 Ball flight trajectories

\section{MATHEMATICAL MODEL}

The golf ball has six degrees of freedom. Its lows of motion about fixed coordinate system are presented by six functions of the time, $\mathrm{z} y \mathrm{x} \mathrm{O}$

\section{A. The Drag Force with layer separation}

The soft field (tennis club), because the weight behind the ball is much smaller than on the front, produces an enormous rush (the local recycling organ rapidly behind a moveable or fixed corpse of a band). The wind will rush into the low-weight region with the soft shoe dragging force. This drag power stops the player from progressing because it works the other way from the path of the wheel. The motivation behind a variety of golf balls therefore is based on the Euler norm that represents the split into the coating, which is probable to happen in fields where the weight rises (the ground sheet next to the golf ball). So showing pimples on the bowling ball means that the panel is not divided into sensitive consequences until it is at the back of the table.

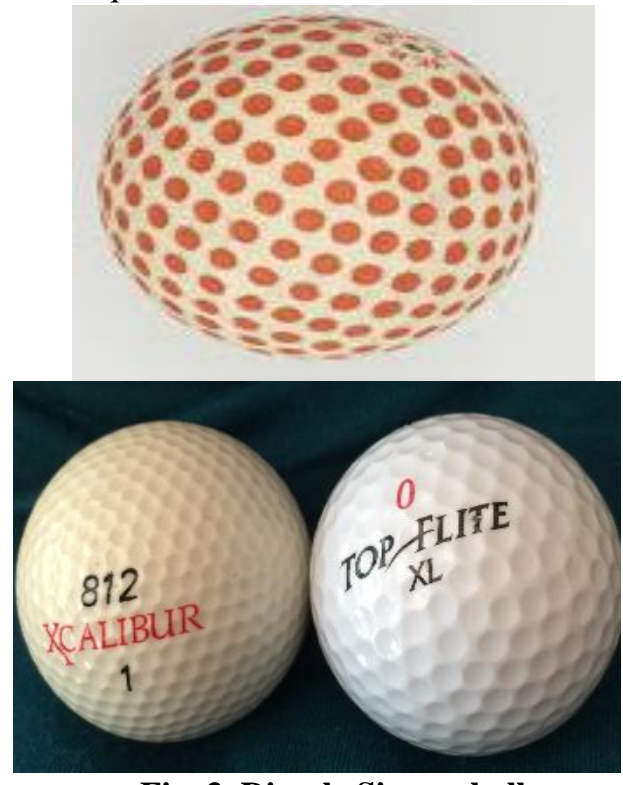

Fig. 3. Dimple Size on ball

\subsection{The Ball Aerodynamics Significance}

In fluid transports, the volume of the Reynolds $(\mathrm{Re})$ is a dimensionless number that indicates for certain Flow conditions the proportion of the inertial forces to the viscosity. The amount for Reynolds is an significant parameter that defines whether fluid circumstances result in laminar or dynamic stream The impact ratio in wind energy encountered during the progress of our control of the field aircraft circumstances relies on the amount for Reynolds. The foundation for this reliance is the move from laminary to messy plans, as the quantity of Reynolds proved. This change takes place on Re St 3x 105, when the drag coefficient shows a drastic reduction. The main aim is to create a mathematical model and to perform numerical recreations on the way a golf ball, taking the impacts and the changes into account.

\section{B. The Magnus effect}

The Magnus effect is a discernible wonder that is regularly connected with a spinning item traveling through a liquid. The way of the spinning article is avoided in a way that is absent when the item isn't spinning. 


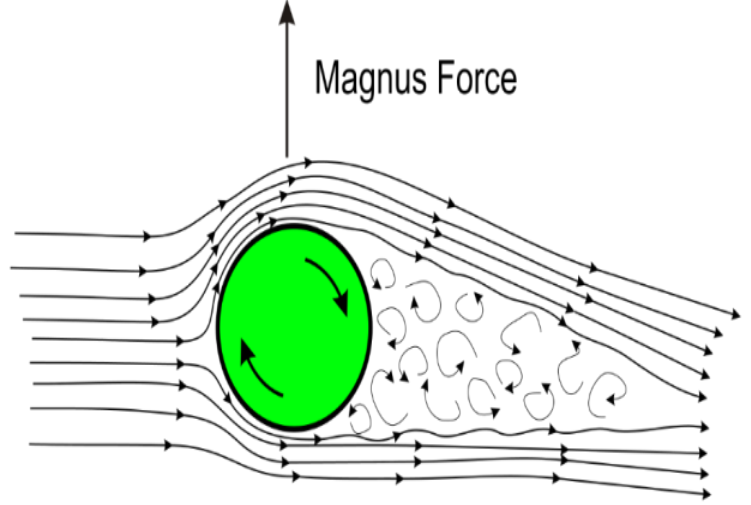

Fig. 4. Magnus Force

The most promptly noticeable instance of the Magnus effect is the point at which a spinning circle (or chamber) bends from the circular segment it would pursue on the off chance that it were not spinning.

Top spin in ball games is characterized as turnabout an even pivot opposite to the course of movement that moves the top surface of the ball toward movement. Under the Magnus effect, top spin creates a descending swerve of a moving ball, more prominent than would be delivered by gravity alone. Reverse-pivot delivers an upwards power that drags out the flight of a moving ball. Likewise side-turn makes swerve either side as observed during some baseball pitches.

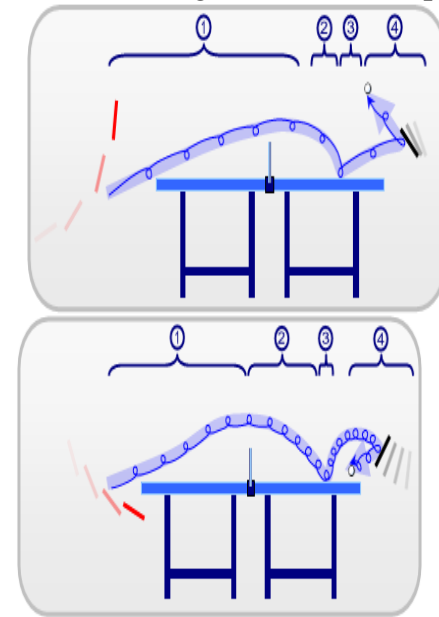

Fig. 5. The affect the trajectory of the ball during its flight and its reaction upon impact

It is likewise a significant factor in the investigation of the effects of spinning on guided rockets - and makes them designer utilizes, for example in the plan of rotor boats and Flettner planes.

The Magnus force is equal to

$$
F_{\mathrm{M}}=\frac{8}{3} \pi r^{3} \rho \omega v
$$

The force is directed upwards for backspin and downwards for topspin

$$
F_{\mathrm{M}}=\frac{1}{2} \rho C_{\mathrm{L}} A v^{2}
$$

Unpredictable, but aerodynamics are also well studied, is the process by which a stormy wake develops in an airflow behind an organ. The meager limiting layer is at some stage de-distant from the corpse ("flow segregation"), and this is where the consciousness starts to develop. It is said that, because of the brushing of the skins and viscosity, Magnus himself postulated the Magnus effect as hypothermic, with laminar stream. However, in comparisons with the effects in the Magnus effect the effect is physically small [5]. In some circumstances, the Magnus effect causes a deflection opposite to that in the Magnus effect.

\section{MODEL FORMULATION}

The correct manner to describe a tennis ball's path is to bring it as an item in movement and to obey the second Newton rule of movement. This law says that an object's acceleration relies on two factors, namely: the net pressures which work on the item and its mass.

\section{A. The drag coefficient}

If the ball joins the atmosphere, the ball triggers water droplets, so that the water bubbles are equal to the level of the energy that is nonetheless aimed towards the back direction of the car as shown in the route $\mathrm{V}$.

$$
\mathrm{fa}(\mathrm{fd}, \mathrm{V}, \mathrm{A}, \mathrm{pv})=0
$$

Here $\mathrm{fa}=\mathrm{a}$ five argument function. Here. Now that you have taken the correct hand to null in any unit agreement, the relation mentioned in the assessment research can be expressed as just dimensionless collections using the Buckingham $\beta$ rule. The two meetings are the amount of Reynolds in this scenario

$$
\mathrm{c}_{\mathrm{d}}=\frac{2 \mathrm{~F}_{\mathrm{d}}}{\rho \mathrm{u}^{2} \mathrm{~A}}
$$

What type of drag coefficient is measured is the target region dependent on. The target region is the expected facial region of the car for cars and many distinct items. The cross-sectional region of the car may not really depend on where the cross-section is placed. The references region for the airfoils, for example, is the ostensible base region for a domain $\mathrm{A}=\alpha \mathrm{r} 2$ notice this is not a ground region= $4 \mathrm{r} r 2$. As this is very distinct from the face region in particular, the previous drift indicators are usually small, considerably smaller than for a car with comparable friction, face and velocity. The drag strength of 2 items with a comparable contact region traveling by a fluid at a comparable velocity corresponds to their respective drag indices. For upstream coated items, the coefficients could be significantly less than 1 , for streamlined items. The drag coeffquent $\mathrm{c} \mathrm{d}$ is shown to be an aspect of Bejan (Be e), Reynolds amount ( $\mathrm{Re})$ and the ratio of moist region $\mathrm{A} w$ to frontal region $\mathrm{A} \mathrm{f}$

$$
\mathrm{c}_{\mathrm{d}}=\frac{\mathrm{A}_{\mathrm{w}}}{\mathrm{A}_{\mathrm{f}}} \frac{\mathrm{Be}}{\operatorname{Re}_{\mathrm{L}}^{2}}
$$

Where

ReLis the Reynold Number and L is related to fluid path length

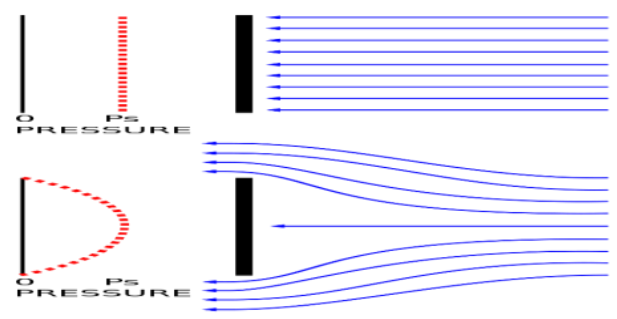

Fig. 6. Flow around a plate 

HIGH TURNING VELOCITY TRAJECTORIES TRACKING PREDICTION

$\mathrm{F}_{\mathrm{d}}=\frac{1}{2} \rho \mathrm{u}^{2} \mathrm{c}_{\mathrm{d}} \mathrm{A}$

The drag equation

$$
\mathrm{F}_{\mathrm{d}}=\frac{1}{2} \rho \mathrm{u}^{2} \mathrm{c}_{\mathrm{d}} \mathrm{A}
$$

The account is basically that the pulling power on every item corresponds to the liquid thickness and to the comparative stream rate between the item and the liquid on the surface.

The velocity of the noise is appropriate in a compressible stream, and $\mathrm{C} \mathrm{d}$ is also part of Mach number $\mathrm{M}$ a.

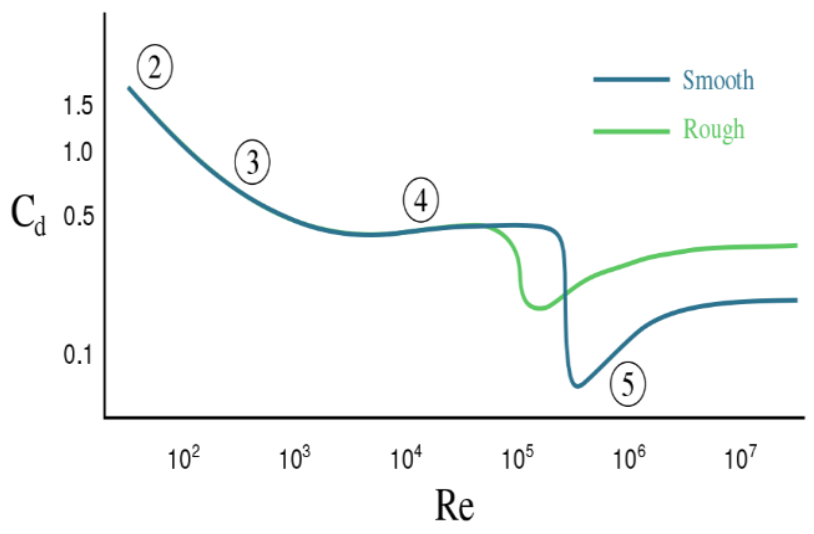

Fig. 7. The boundary layer around

The body needs to be linked with the outside of a body for whatever length of time to achieve a smooth drag factor, so it is limited by the wake. Cd for a sphere as a function of the artifacts and viscosities are reduced [24]. The stream around the item is not vicious at a tiny Reynolds amount, but rather laminar, even if isolated from the external part of the item. On the front, the $\mathrm{C} d$ of a real table tray would be smaller than 1 ; in reality, the rear sucked: a positive (in comparison with the situation). The total $\mathrm{Cd}$ is frequently given in a real cabinet in front of the stream. 22] Flow models and therefore the $\mathrm{d}$ for certain shapes may change with the amount Reynolds and the hardness of the substrates.

\section{B. The Body Flow}

The drag force on a body could be divided into two components, namely frictional drag (viscous drag) and pressure drag (form drag)

$\mathrm{c}_{\mathrm{d}}$

$$
\begin{gathered}
=\frac{2 F_{d}}{\rho v^{2} A} \\
=c_{p}+c_{f} \\
=\frac{1}{\rho v^{2} A} \int_{S} d A\left(p-p_{o}\right)(\hat{\mathbf{n}} \cdot \hat{\mathbf{i}})+\frac{1}{\rho v^{2} A} \int_{S} d \hat{A}(\hat{\mathbf{t}} \cdot \hat{\mathbf{i}}) \mathrm{T}_{\mathrm{w}}
\end{gathered}
$$

$$
\underset{c_{p}}{\omega} \quad \widetilde{\omega}
$$

\section{a. Lift coefficient}

The lift coefficient $C_{\mathrm{L}}$ is defined by

$C_{\mathrm{L}} \equiv \frac{L}{q S}=\frac{L}{\frac{1}{2} \rho u^{2} S}=\frac{2 L}{\rho u^{2} S}$

Resulting in a coefficient: $C_{\mathrm{L}, a e r} \equiv \frac{L}{q c s}$, the second axis is $S_{\text {mar }}=t s$

Resulting in a different coefficient: $C_{\mathrm{L}, \operatorname{mar}} \equiv \frac{L}{q t s}$

The ratio between these two coefficients is the thickness ratio

$C_{\mathrm{L}, \operatorname{mar}} \equiv \frac{c}{t} C_{\mathrm{L}, a e r}$ Reynolds number besides large numbers from Reynold, large

\section{RESULT}

Our aircraft path simulation scheme is shown in the figure. For air density and dimple properties calculations (dim-ple volume and width, dimple numbers), entry heat, moisture and elevation can be added to users. Our scheme calculates the trajectory of a coin with the 4th stage Runge-Cutta technique, when the original projectile velocity and angular velocity is provided. A comparative of observed and displayed dis-tances is shown in Table II. The median mistake is around $3.4 \%$. As can be seen, under different circumstances, the virtual ranges are quite comparable to true ranges. The flight simulation system proposed in this report can provide different impacts for games reflecting alterations in wind and dimple features. This increase the truth of a golfing screens by calculating the drag and raise rates exactly.

Table 1: Comparison of distances recreated and analyzed

\begin{tabular}{lllllll}
\hline $\begin{array}{l}\text { Sr. } \\
\text { No. }\end{array}$ & V(m/s) & $\begin{array}{l}\text { Angle } \\
(\text { deg. })\end{array}$ & $\begin{array}{l}\text { Spin } \\
(\mathbf{1 p m})\end{array}$ & $\begin{array}{l}\text { Real } \\
\text { Cany } \\
(\mathrm{m})\end{array}$ & $\begin{array}{l}\text { Virtual } \\
\text { Cany } \\
(\mathrm{m})\end{array}$ & $\begin{array}{l}\text { Error } \\
(\mathbf{\%})\end{array}$ \\
\hline $\mathbf{1}$ & 71.98 & 8.7 & 2391 & 274.59 & 258.47 & 6.2 \\
\hline $\mathbf{2}$ & 72.22 & 9.6 & 2600 & 279.15 & 266 & 5.23 \\
\hline $\mathbf{3}$ & 73.34 & 10.12 & 2400 & 267 & 265 & 4.24 \\
\hline $\mathbf{4}$ & 76.33 & 13.12 & 2350 & 268.3 & 276 & 3.34 \\
\hline $\mathbf{5}$ & 78.10 & 13.23 & 2217 & 281.12 & 288 & 2.87 \\
\hline 6 & 79.21 & 14.01 & 2200 & 282 & 287 & 2.50 \\
\hline
\end{tabular}

\section{REFERENCES}

1. Aoki K, Muto K, O kanaga H, Nakayama Y (2009) Aerodynamic characteristic and flow pattern on dimples structure of a sphere. Flucome 10th International Conference on Fluid Control, Measurement and Visualization.

2. Aoki K, Muto K, O kanaga H (2010) Aerodynamic characteristics and flowpattern of a golf ball with rotation. Procedia Engineering 2: 2431-2436.

3. Aoki K, Nonaka M, Goto T. Aerodynamics and flying characteristic for thesurface structure of the golf ball. Proceedings of the School of EngineeringTokyo University 44.

4. Aoki K, Ohike A, Yamaguchi K, Nakayama Y (2003) Flying characteristics and flow pattern of a sphere with dimples. Journal of visualization 6: 67-76.

5. Naruo T, Mizota $\mathrm{T}$ (2014) The influence of golf ball dimples on aerodynamic characteristics. Procedia Engineering 72: 780-785.

6. Myers TG, Mitchell SL (2013) A mathematical analysis of the motion of an inflight soccer ball. Sports Engineering 16: 29-41.

7. Baek S, Kim M (2013) Flight trajectory of a golf ball for a realistic Game. International Journal of Innovation, Management and Technology 4: 346.

8. Alam F, Steiner T, Chowdhury H, Moria H, Khan I, et al. (2011). A study of golfball aerodynamic drag. Procedia Engineering 13: 226-231.

9. Mac Kenzie S.J., Springing's E.J., A three-dimensional forward dynamics model of the golf swing, Sport 
Engineering, 2009, 165-175.

10. Zheng N., Barrentine S. W., Fleisig G. S., Andrews J. R., Kinematic analysis of swing in pro and amateur golfers, Int. J. Sports Med., 29 (6), 2008, 487-493.

11. Healy A., Moran K., Dickinson J., Hurley C., Smeaton A., O'Connor N., Kelly P., Haahr M., Chockalingam N., Analysis of the 5 iron golf swing when hitting for maximum distance, Journal of Sports Sciences, 29, 2011, 1079-1088

12. Xu Z., A Study of Impact between Golf Ball and Face of Golf Club Head, BSc MEng Project Report, 2015, 1-21.

13. Maruoka K., Sakagami S., Yamada K., Nakagawa N., Sekiguti Y., Dynamic Impact Characteristics of Golf Ball Materials, Materials and Science in Sports, TMS, 2001, pp. 146-159.

14. Mase T., Experimental Benchmarking Golf Ball Mechanical Properties, X International Congress and Exposition on Experimental and Applied Mechanics, 2004.

15. Umakant B. Gohatre, Venkat P Patil, Sanjay Gaur, "Comparative Estimation of Trajectory based Tracking System and Impact of Subsequent on Projectile Course Prediction Techniques", IJCEM International Journal of Computational Engineering \& Management, volume 20, Issue 5, ISSN (Online): 2230-7893, September 2017

16. Wu Z., Sogabe Y., Arimitsu Y., Determination of Material Properties of Golf Ball and Optimization of Golf Clubhead, SEM Annual Conference on Experimental and Applied Mechanics, Vol. 3, 2009, 1924-1931.

17. Alam F., Chowdhury H., Moria H., Bray R.L., Subic A., A Comparative Study of Golf Ball Aerodynamics, 17th Austral

18. Barber R., Golf Ball Flight Dynamics, Cornell University, A\&EP 434 Final Project, Professor Lovelace, 2007.

19. Baek S., Kim M., Flight Trajectory of a Golf Ball for Realistic Games, International Journal of Innovation, Management and Technology, Vol. 4, No. 3, 2013, 346-350.

20. Ivanov A.I., Investigation of three-dimensional tennis ball flight, Journal Mechanics of Machines, year XXII, book 2, 2014, 34-37. (in Bulgarian)

21. Nikolov S., Nedev V., Bifurcation analysis and dynamic behaviour of an inverted pendulum with bounded control, J. of Theoretical and Applied Mechanics, vol. 46, No 1, 2016, 17-32.

22. Umakant B. Gohatre, Venkat P. Patil "A Robust Approach towards Unknown Transformation, Regional Adjacency Graphs, Multigraph Matching, Segmentation Video Frames From Unnamed Aerial Vehicles (UAV)", International conference on Electrical, Electronics, Materials and Applied Science (ICEEMAS-2017), 22nd and 23rd December 2017, Organized by Swami Vivekananda Institute of Technology, Secunderabad, Telangana, India

23. Robinson G., Robinson I., The motion of an arbitrarily rotating spherical projectile and its application to ball games, PhysicaScripta, Vol. 88, N 1, 2013, 018101, 17 p.

24. Umakant B. Gohatre, Venkat P. Patil, ChetanPatil, "Performance Evaluation of Feature Types For Object Detection and Classification", International Journal of Management, Technology And Engineering Volume 8, Issue X, OCTOBER/2018 ISSN NO : 2249-7455, Page 1377

25. Lukas T.D., Computational modeling of the Golf Stroke, $\mathrm{PhD}$, Glasgow Theses Service, 1999

26. Umakant B. Gohatre, Venkat P. Patil, "Performance analysis of Novel Technique for Video Based Real Time Object Detection in 2 Dimensional and 3 Dimensional Visual System" IJEECS, Volume 6, Issue 9, ISSN 2348-117X, September 2017

\section{AUTHORS PROFILE}

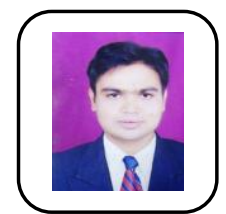

Umakant Bhaskarrao Gohatreis graduatedin BE and $\mathbf{M}$. $\mathbf{E}$ andis working as faculty of engineering and technology working since 6 years under Engineering college of university of Mumbai affiliated colleges. Currently working as Asst. Professor in Smt. Indira Gandhi engineering college, Navi Mumbai since 6 years His area of research is Mathematical computational Models, Machine Learning, Image Processing, and Computer Vision. Currently he is research scholar of Madhav University, Pindwara, Rajasthan, India.

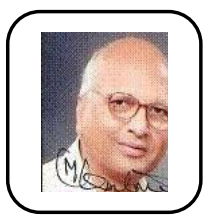

Dr. C. Ram Singla , 45+ Years of experience in the field of engineering education at various positions including Director, Principal, Advisor, HOD etc Served various institutions of Haryana and Rajasthan and widely connected with educationists and technocrats all over India .First Ph.D. in the field of electronics engineering from MDU, Rohtak. Currently he is research Guide and HOD Electronics and Communication Engineering Department in Madhav University, Pindwara, Rajasthan.

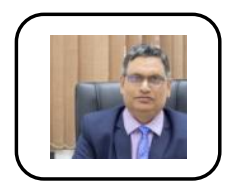

Venkat P Patilis graduatedin BE and M. TECH andis working as faculty of engineering and technology working since 30 years under various engineering colleges of university of Mumbai affiliated colleges. Currently working as

Vice-Principal /Associate Professor in Smt. Indira Gandhi engineering college, Navi Mumbai since 25 years. His area of research is image processing and computer vision. Currently he is research scholar of Madhav University, Pindwara, Rajasthan, India. 